\title{
Regulation of alternative splicing of Bcl-x by IL-6, GM-CSF and TPA
}

\author{
Chang You LI ${ }^{1}$, Jia You CHU ${ }^{1, *}$, Jian Kun YU ${ }^{1}$, Xiao Qin HUANG ${ }^{1}$, Xiao Juan LIU ${ }^{1}$, Li SHI ${ }^{1}$, Yan Chun CHE ${ }^{1}$, \\ Jiu Yong XIE, ${ }^{2, *}$
}

${ }^{1}$ Institute of Medical Biology, Chinese Academy of Medical Sciences and Peking Union Medical College, Kunming 650118, China. ${ }^{2}$ Department of Physiology, Faculty of Medicine, University of Manitoba, 420 BMSB, 730 William Ave., Winnipeg, MB R3E 3J7, Canada.

\begin{abstract}
The splicing of many alternative exons in the precursor messenger RNA (pre-mRNA) is regulated by extracellular factors but the underlying molecular bases remain unclear. Here we report the differential regulation of Bcl-x pre-mRNA splicing by extracellular factors and their distinct requirements for pre-mRNA elements. In K562 leukemia cells, treatment with interleukin-6 (IL-6) or granulocyte-macrophage colony stimulating factor (GM-CSF) reduced the proportion of the Bcl-xL variant mRNA while treatment with 12-O-tetradecanoylphorbol 13-acetate (TPA) had no effect. In U251 glioma cells, however, TPA efficiently increased the Bcl-xL level. These regulations were also seen for a transfected splicing reporter mini-gene. Further analyses of deletion mutants indicate that nucleotides 1-176 of the downstream intron are required for the IL-6 effect, whereas additional nucleotides 177-284 are essential for the GM-CSF effect. As for the TPA effect, only nucleotides 1-76 are required in the downstream intron. Thus, IL-6, GM-CSF and TPA differentially regulate $\mathrm{Bcl}-\mathrm{x}$ splicing and require specific intronic pre-mRNA sequences for their respective effects.
\end{abstract}

Keywords: alternative splicing, $b c l-x$ gene, cytokine, TPA, pre-mRNA element.

\section{INTRODUCTION}

Alternative pre-mRNA splicing is an important way of gene regulation in metazoans [1]. It is estimated to be present in about 60 percent of human genes [2], resulting in a large number of splice variants. This likely contributes to protein diversity beyond the relatively small number of human genes [3]. Many splice variants have distinct functions and can be regulated by extracellular factors, but the molecular bases of the regulations remain largely unclear [1,4]. In several cases, pre-mRNA elements involved in responses to external factors have been identified [5-9]. In one case, the extracellular signal-regulated kinase (ERK) was found to directly phosphorylate the splicing factor Sam68 in regulating CD44 splicing [10].

A number of genes involved in cell proliferation and apoptosis undergo alternative splicing, producing variants with different or even antagonistic functions [11]. Bcl-x, a $b c l-2$ gene family member, generates several protein isoforms including Bcl-xL and Bcl-xS by alternative splicing $[12,13]$. The inclusion of the 189-nucleotide (nt) Bcl-xL exonic sequence leads to the insertion of 63 amino acids

\footnotetext{
*Correspondence: Jia You CHU and Jiu Yong XIE

E-mail: chujy@public.km.yn.cn or xiej@cc.umanitoba.ca.
}

in Bcl-x in a highly conserved region of the Bcl-2 family proteins [13]. Bcl-xL can protect cells from apoptosis [13, 14]. Genetic depletion of Bcl-xL in mice lead to massive neuronal death in the nervous system [15]; cancer cells with Bcl-xL splicing inhibited are more sensitive to apoptosis upon chemotherapeutic drug treatment [16-18]. On the contrary, Bcl-xS inhibits cell survival induced by bcl-2 [13]. Therefore, the Bcl-x products can be pro- or anti-apoptotic depending on the result of alternative splicing of its pre-mRNA. Expressions of the two variants are differentially regulated among tissues, during development and in diseases $[13,19,20]$. In cultured cells, Bcl-x splicing can be regulated by ceramide [21]. It is thus likely that Bcl-x splicing can be regulated by a variety of extracellular factors and this regulation plays a role in cell growth and cell death. However, it is not clear how different signals regulate Bcl-x splicing and what are the pre-mRNA sequences required.

To establish a model for Bcl-x splicing regulation by signals related to cell survival or death, we screened extracellular factors for changes in $\mathrm{Bcl}-\mathrm{xL} / \mathrm{Bcl}-\mathrm{xS}$ splicing patterns and recapitulated the regulations with mini-gene splicing reporters. We further demonstrated that these extracellular factors required different downstream intronic sequences for their effects on Bcl-x splicing. 


\section{MATERIALS AND METHODS}

\section{Cell culture, treatment, and transient transfection assays}

K562 and U251 cells were cultured in RPMI 1640 media plus $10 \%$ fetal bovine serum in 6 -well plates at $37^{\circ} \mathrm{C}$. Recombinant IL-6 and GM-CSF were kind gifts from Dr. Dai CB and Li ZH (Institute of Medical Biology, Chinese Acamey of Medical Sciences and Peking Union Mecical College) respectively, who purified them from bacteria and confirmed their activities [22, 23]. TPA was from Alexis Biochemicals (Switzerland). Erigeron breviscapus was from BioMedicine Industry Ltd. (Yunnan, China) [24, 25]. IL-6 (20 ng/ml), GM-CSF $(20 \mathrm{ng} / \mathrm{ml})$, TPA $(20 \mathrm{ng} / \mathrm{ml})$ or erigeron breviscapus $(30 \mathrm{ng} /$ $\mathrm{ml}$ ) were applied respectively to cells and kept for various periods of time before RNA extraction. For mini-gene splicing reporter assays, about $10^{6}$ cells were transfected with plasmids using LipoFectamine2000 (Invitrogen) according to the manufacturer's instructions. After about $16 \mathrm{~h}$, cells were washed with ice-cold phosphate-buffered saline and then lysed for RNA extraction with Trizol (Invitrogen).

\section{RT-PCR assay of the Bcl-x splice variants}

One microgram of total cellular RNA was used for $20 \mu 1$ reverse transcription [RT: $2 \mu \mathrm{l}$ of $10 \times$ buffer, $2 \mu \mathrm{l}$ of dNTP $(10 \mathrm{mM}$ each), $1 \mu \mathrm{l}$ of RNase inhibitor ( 20 units), $1 \mu 1$ of oligo-dT, $1 \mu 1$ of MMLV reverse transcriptase, plus DEPC-treated distilled water) at $42^{\circ} \mathrm{C}$ for $1 \mathrm{~h}$, followed by heating at $95^{\circ} \mathrm{C}$ for $5 \mathrm{~min}$. The RT products were used either directly for polymerase chain reaction (PCR) or saved frozen.

For PCR, the bcl-x sense primer is 5'-CATGGCAGCAGTAAAGCAAG-3', and the antisense primer is 5'-GCATTGTTCCCATAGAGTTCC-3'. It gives rise to PCR products of 351 and 162 base pairs (bp) for Bcl-xL and Bcl-xS, respectively. RT-PCR of the glyceraldehyde-3-phosphate dehydrogenase $(G A P D H)$ gene was used as the control for the loading of RNA/RT products. For the PCR of transfected pBcl-x plasmids, the sense primer is 5'-CATGGCAGCAGTAAAGCAAG-3' (in the exon 2 of $b c l-x$ gene), and the antisense primer is 5'-ACCCGGATCCAGTTGTGCCA-3' (in the downstream insulin exon of the vector). It gives rise to PCR products of $150 \mathrm{bp}$ and $339 \mathrm{bp}$. All PCR products were separated in $2 \%$ agarose gels containing $0.01 \%$ ethidium bromide. Band intensities were quantified with the Scion Image software (Scion Corporation).

\section{$B c l-x$ mini-gene and mutant plasmids construction}

Human $B C L-x$ genomic DNA was amplified with sense primer $\mathrm{F} 1$ (5'-AGTCGGGCCCAGGATACAGCTGGAGTCAG-3') and anti-sense primer F2 (5'-CTGTTCTAGAGAGTGCCATACACGCAAACTTTG-3') to generate a 1020 bp fragment that contains the 3 ' end 316 bp of exon 2, the $189 \mathrm{nt} \mathrm{Bcl-xL-specific} \mathrm{exon} \mathrm{sequence}$ and the 5 ' end $515 \mathrm{bp}$ of the downstream intron $[13,26]$. The PCR fragment (Bcl-x1) was cloned between the ApaI and $\mathrm{XbaI}$ sites of vector pL53In, generously provided by Dr. Harald Konig [5].

Deletions from two ends of the Bcl-x1 insert were made by PCR with primers containing $A p a \mathrm{I}$ and $\mathrm{Xba \textrm {I }}$ site. The sense primer is 5'AGTCGGGCCCATCCTGGCACCTGGCAG-3' for all the deletion mutants and the antisense primers are: 5'-CTGTTCTAGAGATACAGAAGAAGGGCTG-3' for pBcl-x2, 5'-CTGTTCTAGAATTTGTATTTCCAAGGAG-3' for pBcl-x3, and 5'-CTGTTCTAGACACATAGGCTACAGTTTTC-3' for pBcl-x4. The amplified PCR fragments were cloned into pL53In and confirmed by sequencing the Bcl-x inserts.

\section{RESULTS}

\section{Regulation of Bcl-x splicing by IL-6, GM-CSF in $K 562$ cells and by TPA in U251 cells.}

$\mathrm{Bcl}-\mathrm{xL}$ and $\mathrm{Bcl}-\mathrm{xS}$ variants are produced through the two alternative 5' splice sites downstream of exon 2 in Bcl-x pre-mRNA [13] (Fig. 1A). To establish a regulatory system for this alternative splicing event, we screened cell lines and extracellular factors for inducible changes in Bcl-xL/Bcl-xS splicing patterns with RT-PCR.

In K562 leukemia cells, RT-PCR generated mainly two bands in agarose gels (Fig. 1B, C). Sequencing of purified DNA indicates that the upper band contains Bcl-xL and the lower one Bcl-xS. Treatment of the cells with interleukin11 (IL-11) or TPA did not substantially change the Bcl-xL/ Bcl-xS splicing pattern (lanes 2 and 5, respectively). However, treatment with the cytokine IL-6 or GM-CSF greatly reduced the Bcl-xL product (about $70 \%$ reduction), leaving mainly Bcl-xS. The Bcl-xL product almost disappeared at 12 and $6 \mathrm{~h}$ after treatment with IL-6 and GMCSF, respectively (Fig. 1C). These suggest that IL-6 or GM-CSF specifically reduces the proportion of the Bcl$\mathrm{xL}$ mRNA in K562 cells.

Of the two factors (IL-11 and TPA) that did not substantially change the $\mathrm{Bcl}-\mathrm{xL} / \mathrm{Bcl}-\mathrm{xS}$ splicing pattern (Fig. $1 \mathrm{~B}$, lanes 2 and 5), however, TPA is known to regulate the splicing of other alternative exons, particularly those of the cell surface molecules CD44 and CD45 [5, 6]. We thus tested TPA with more cell lines for Bcl-x splicing changes. We found that in U251 human glioma cells Bcl$\mathrm{xL}$ was increased from $75 \%$ to $92 \%$ after TPA treatment (Fig. 1D, lanes 1 and 2). This increase was prevented by erigeron breviscapus, which has been reported to have an inhibitory effect on protein kinase C (PKC) [24, 25]. Moreover, treatment with erigeron breviscapus alone eliminated the Bcl-xL product (lane 4). These suggest that TPA promotes the $\mathrm{Bcl}-\mathrm{x}$ splicing toward the production of $\mathrm{Bcl}-$ xL mRNA in U251 cells, likely through the PKC pathway.

Taken together, cytokines IL-6 and GM-CSF repress alternative splicing of the Bcl-xL mRNA whereas TPA increases it. Moreover, the regulation by TPA is observed only in U251 but not K562 cells. These suggest that the splicing regulations are extracellular factor- and celldependent.

\section{A $B c l-x$ mini-gene contains elements sufficient for IL-6, GM-CSF and TPA regulation of Bcl-x pre-mRNA splicing}

By aligning the human Bcl-xL, Bcl-xS cDNAs with the $B c l-x$ genomic DNA from the GenBank $[13,26]$, the splice junctions of the two alternative 5'splice sites are annotated to be AGgtagtg (5'splice site for Bcl-xS, lower case letters representing the intron sequence) and GGgtaaga (5'splice 
A
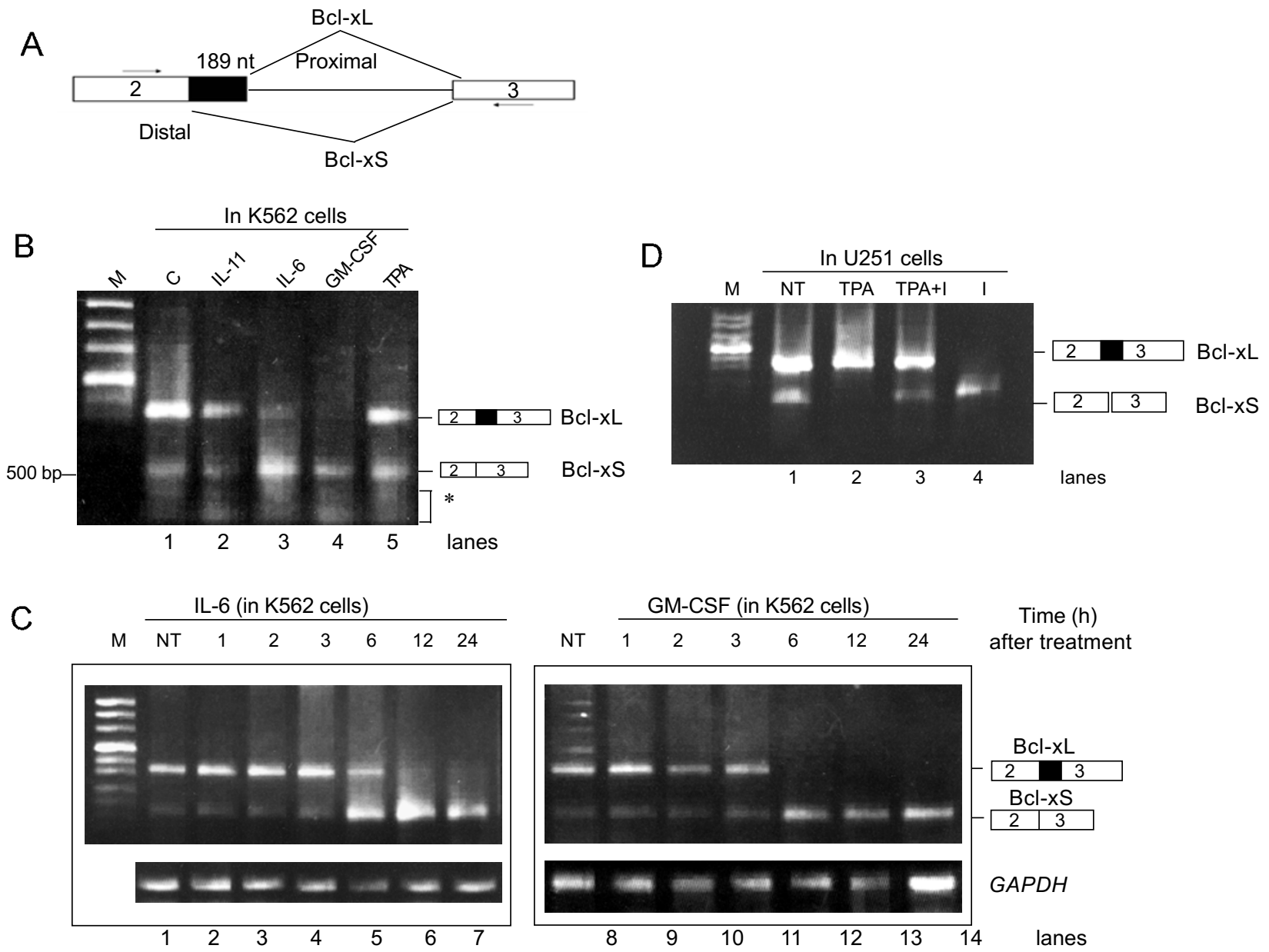

Time (h) after treatment

Fig. 1 Bcl-x pre-mRNA and its splicing regulations by extracellular factors. (A) Structure of the pre-mRNA region related to Bcl-xL/Bcl-xS splicing. (B) Agarose gel of RT-PCR products from K562 cells either non-treated or treated for $6 \mathrm{~h}$ with IL-11, IL-6, GM-CSF or TPA (lanes 1-5), respectively. The 189 nt-included or -excluded products are indicated as boxes to the right. The asterisk indicates minor bands of unknown identity in this gel. (C) Time course of the IL-6 (left panel) and GM-CSF (right panel) effects on Bcl-x splicing. GAPDH products are shown below the Bcl-x gels as an RNA loading control. (D) RT-PCR from U251 cells treated with TPA or inhibitor (I) erigeron breviscapus. Boxes are exons and horizontal lines introns. The black box represents the $189 \mathrm{nt} \mathrm{Bcl-xL-specific} \mathrm{exon} \mathrm{segment.} \mathrm{M:} 100$ bp DNA ladder. NT: not treated.

site for Bcl-xL), slightly different from the consensus sequence of the constitutive 5'splice site "AGgtragt (r: A or G) in GT-AG introns [27]. To identify specific premRNA sequences involved in the regulation of Bcl-x splicing, we wanted to first narrow down the minimal RNA sequences that are sufficient for the regulations by IL-6, GM-CSF and TPA. Therefore, we amplified a genomic DNA fragment of the human $b c l-x$ gene that covers the $3^{\prime}$ end $316 \mathrm{bp}$ of exon 2, the $189 \mathrm{bp} \mathrm{Bcl-xL-specific} \mathrm{sequence}$ and the $5^{\prime}$ end $515 \mathrm{bp}$ of the downstream intron, and cloned it into a vector (pL53In) [5], to make a splicing reporter (pBcl-x1, Fig. 2A). This plasmid was transfected into K562 or U251 cells and the spliced mRNAs were examined with
RT-PCR for the effects of the above stimuli.

In K562 cells, the transfected Bcl-x1 mini-gene expressed mainly Bcl-xL, similar to the endogeneous products (Fig. 2B, lane 3, and compares with Fig. 1). Treatments with either IL-6 or GM-CSF, but not IL-11 or TPA, strongly decreased Bcl-xL level (Fig. 2B, lanes 4 to 7), leaving mainly $\mathrm{Bcl}-\mathrm{xS}$ products. Thus, the $\mathrm{Bcl}-\mathrm{x} 1$ insert contains elements sufficient for the IL-6 or GM-CSF regulation of Bcl-x pre-mRNA splicing in K562 cells.

In U251 cells, this Bcl-x1 construct expressed Bcl-xL and Bcl-xS at similar levels (Fig. 2C, lane 3). TPA treatment almost eliminated Bcl-xS leaving only Bcl-xL (Fig. 2C, lane 4). Again, erigeron breviscapus prevented this 
A

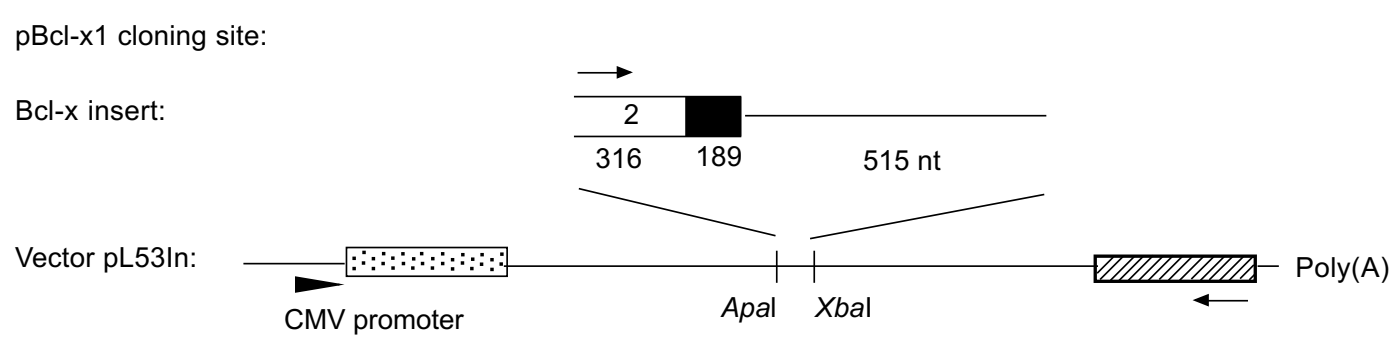

B

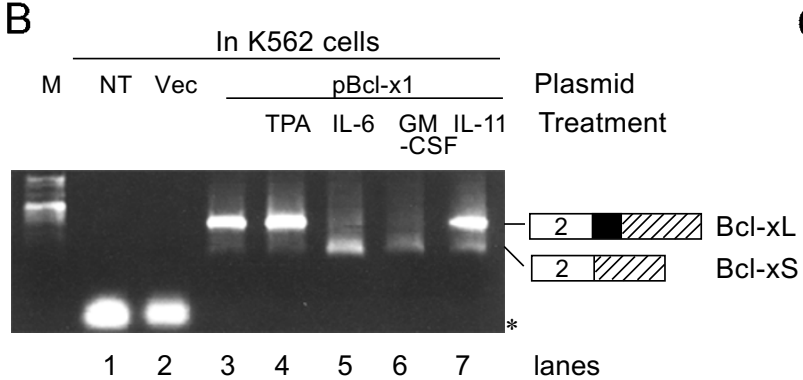

C

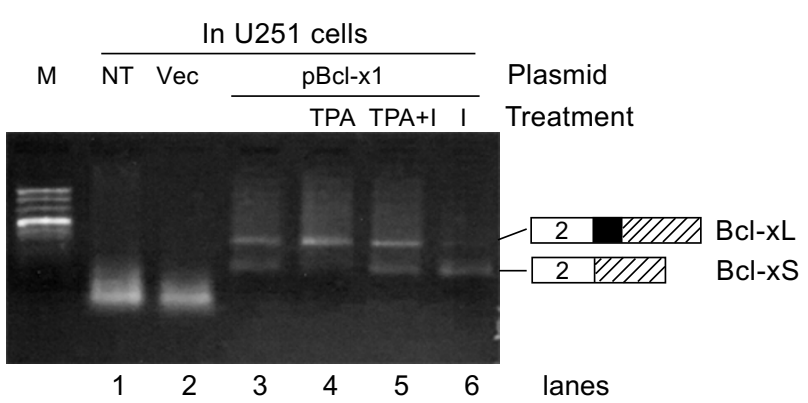

Fig. 2 Responses of the mini-gene splicing reporter of Bcl-x1 to regulations by IL-6, GM-CSF and TPA. (A) The cloning site of Bcl-x1. The arrows represent primers for PCR and arrowhead the CMV promoter. The restriction enzyme sites for cloning are indicated below the intron line. (B) Specific regulation of the Bcl-x1 pre-mRNA splicing by IL-6 and GM-CSF in K562 cells. (C) Regulation of Bcl-x1 pre-mRNA splicing by TPA in U251 cells. Boxes: exons. Black box: 189 nt Bcl-xL-specific sequence. NT: not-treated. Vec: vector pL53In. Asterisk: bands of primers or amplified primer dimer products.

TPA effect (lane 5). Furthermore, erigeron breviscapus alone greatly reduced Bcl-xL level (lane 6). Thus, this Bcl$\mathrm{x} 1$ insert also contains elements sufficient for the TPA regulation of Bcl-x pre-mRNA splicing in U251 cells.

Since this $B c l-x l$ mini-gene contains elements sufficient for the splicing regulations by IL-6, GM-CSF and TPA, it provides a starting substrate for narrowing down the insert and identifying Bcl-x pre-mRNA sequences required by each factor. Also of particular interest to us is whether these required sequences are different for the extracellular factors. We thus went on to identify the minimal inserts and pre-mRNA regions required for these regulations.

\section{Regulation of Bcl-x splicing by IL-6, GM-CSF or TPA requires different intronic pre-mRNA segments}

Most identified regulatory elements of pre-mRNA splicing are within the target exon or within hundreds of nucleotides flanking the exon [1]. We thus chose to first shorten the sequences flanking the $189 \mathrm{nt}$ to identify a minimal Bcl-x insert for each extracellular factor. These constructs contain the $3^{\prime}$ end 211 bp of exon 2 and different lengths of the downstream intron (Bcl-x2 to 4, Fig. $3 \mathrm{~A})$. They were transfected into cells and tested for their responses to different treatments.

$\mathrm{Bcl}-\mathrm{x} 2$ has the shortest insert containing only $76 \mathrm{bp}$ of the downstream intron, Fig. 3A). It expresses very little
Bcl-xL mRNA in K562 cells (Fig. 3B, lane 2), suggesting the loss of Bcl-xL splicing enhancers from Bcl-x1. Treatment with IL-6 did not change this splicing pattern (lane 3). Adding the intron region from nucleotides 77 to 176 in Bcl-x3 increased $\mathrm{Bcl}-\mathrm{xL}$ to be the predominant product (lane 4), suggesting that nucleotides 77-176 contain elements that promote the splicing for the Bcl-xL mRNA. Importantly, the Bcl-xL splicing was almost completely repressed by treatment with IL-6 (lane 5). Thus, the Bcl-x3 insert sequence contains pre-mRNA elements sufficient for IL-6 repression of the Bcl-x splicing for the Bcl-xL mRNA. Further addition of nucleotides 177-284 in Bcl-x4 slightly reduced the Bcl-xL product to about $60 \%$. Surprisingly, this construct lost response to IL-6 (lane $6 \&$ 7), likely due to interference from additional elements between nucleotides 177-284.

In the GM-CSF group, the untreated mutants showed similar Bcl-xL/Bcl-xS splicing pattern as in the IL-6 group (Fig. 3C). However, unlike IL-6, GM-CSF treatment failed to reduce the Bcl-xL mRNA in Bcl-x3 (Fig. 3C, lanes 3 \& 4). Instead, it is in Bcl-x4 where GM-CSF reduced the Bcl-xL mRNA (from $62 \%$ to $33 \%$, lanes $5 \& 6$ ). This suggests that the RNA sequence between 177 and $284 \mathrm{nt}$ in the downstream intron contains elements specifically required for GM-CSF repression of the splicing for the Bcl-xLmRNA. 

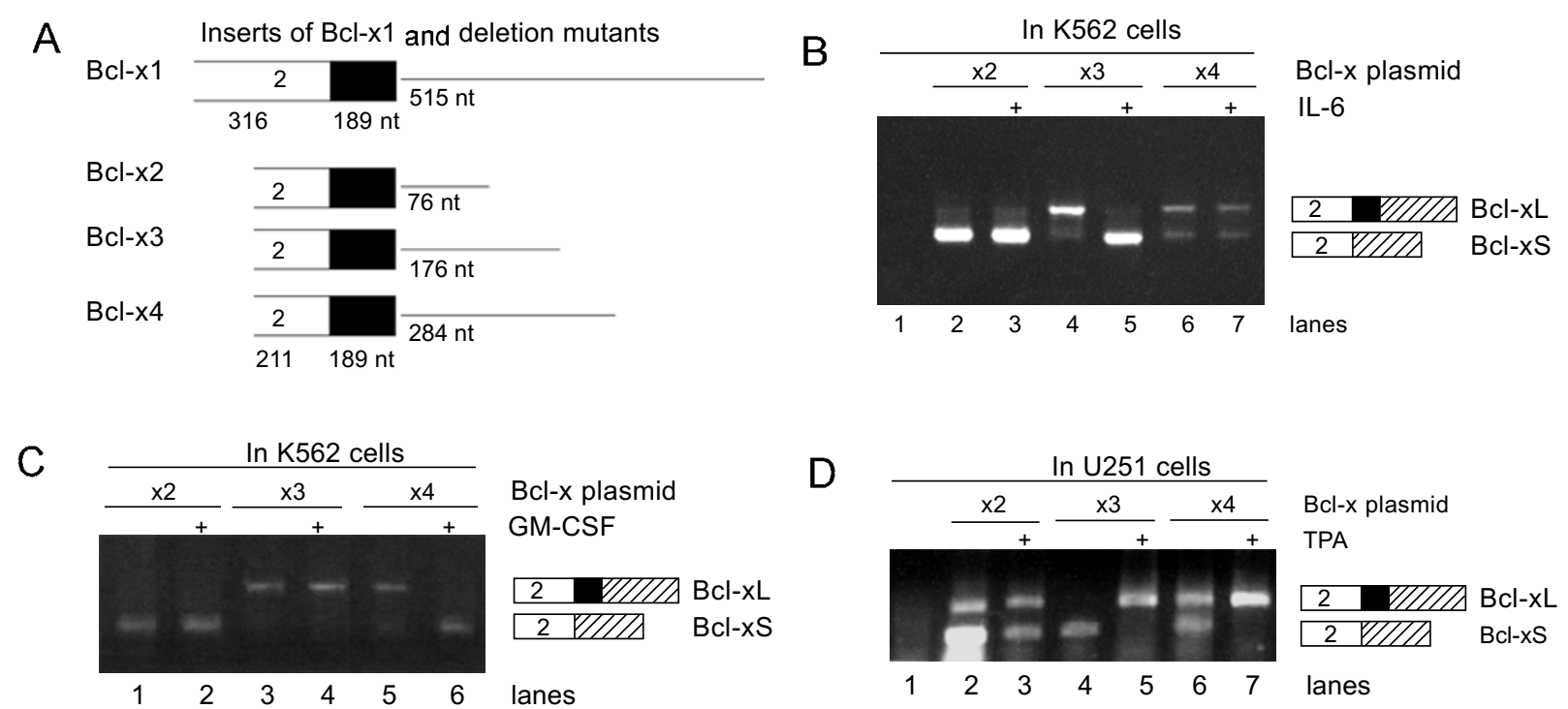

Fig. 3 Differential responses of deletion mutants to splicing regulations by IL-6, GM-CSF and TPA. (A) Inserts of Bcl-x2 to 4 deletion mutants. The numbers of nucleotides flanking the $189 \mathrm{nt}$ are indicated below the exons (box) or introns (line). Also shown are agarose gels of the RT-PCR products of transfected Bcl-x plasmids after treatment with IL-6 (B) or GM-CSF (C) in K562 cells, or with TPA in U251 cells (D). Boxes: exons. Black box: $189 \mathrm{nt} \mathrm{Bcl-xL-specific} \mathrm{sequence.}$

These results indicate that the minimal Bcl-x inserts required for the IL-6 and GM-CSF effects are Bcl-x3 and $\mathrm{Bcl}-\mathrm{x} 4$, respectively. A region specifically required for the GM-CSF effect lies between 177 and 284 nt in the downstream intron but this same region abolishes the IL-6 effect. Thus, although IL-6 and GM-CSF similarly repress the splicing for Bcl-xL, they require different segments of the Bcl-x pre-mRNA.

In the TPA group, we transfected the mutants into U251 cells and tested their responses to the splicing regulation. These mutants showed splicing patterns only slightly different from those in $\mathrm{K} 562$ cells except Bcl-x3, which in contrast produced mainly Bcl-xS (Fig. 3D). This is likely due to a much weaker effect in U251 cells than in K562 cells of the elements that favor the splicing for Bcl-xL. TPA treatment increased Bcl-xL in all these mutants, with the strongest effect observed in Bcl-x3 resulting in a complete switch from Bcl-xS to Bcl-xL. The minimal insert sufficient for the TPA effect is in Bcl-x2, in contrast to those for the IL-6 (Bcl-x3) and GM-CSF (Bcl-x4) effects.

The responses of the Bcl-x constructs to IL-6, GMCSF or TPA are summarized in Fig. 4. It shows that the effects of the extracellular factors on Bcl-x splicing require different pre-mRNA segments in the downstream intron.

\section{DISCUSSION}

We have shown that expression of the endogenous
$\mathrm{Bcl}-\mathrm{x}$ variant $\mathrm{Bcl}-\mathrm{xL}$ is specifically repressed by IL-6 and GM-CSF in human K562 leukemia cells and enhanced by TPA in U251 glioma cells. These effects were also observed with mini-gene splicing reporters. We further show that these regulations require different segments of the downstream intron. Thus, different cell signals likely have specific target cis-acting elements in regulating alternative splicing of the same exon.

The changes in Bcl-x splicing were observed about 6 hours after treatment of K562 cells with IL-6 or GM-CSF (Fig. 1C). Particularly after GM-CSF treatment, the Bcl-x mRNA is switched completely from Bcl-xL to Bcl-xS at $6 \mathrm{~h}$. It thus appears that GM-CSF has faster effect on the Bcl-x splicing than IL-6. However, this needs to be addressed by measuring the Bcl-x mRNA levels at time points between 3 and $6 \mathrm{~h}$ to find the exact time when Bcl-x splicing start to change after GM-CSF treatment. Another question is whether protein synthesis is required for the splicing changes caused by these extracellular factors. From the time course, there is enough time for new proteins to be synthesized before splicing starts to change. However, since the observation of splicing changes requires the turnover of existing mRNAs prior to treatment, it is also likely that no new proteins are required for this regulation. Further experiments with protein-synthesis inhibitors should be able to address this question.

For IL-6 and GM-CSF, more detailed studies are required to identify the downstream factors that mediate their 


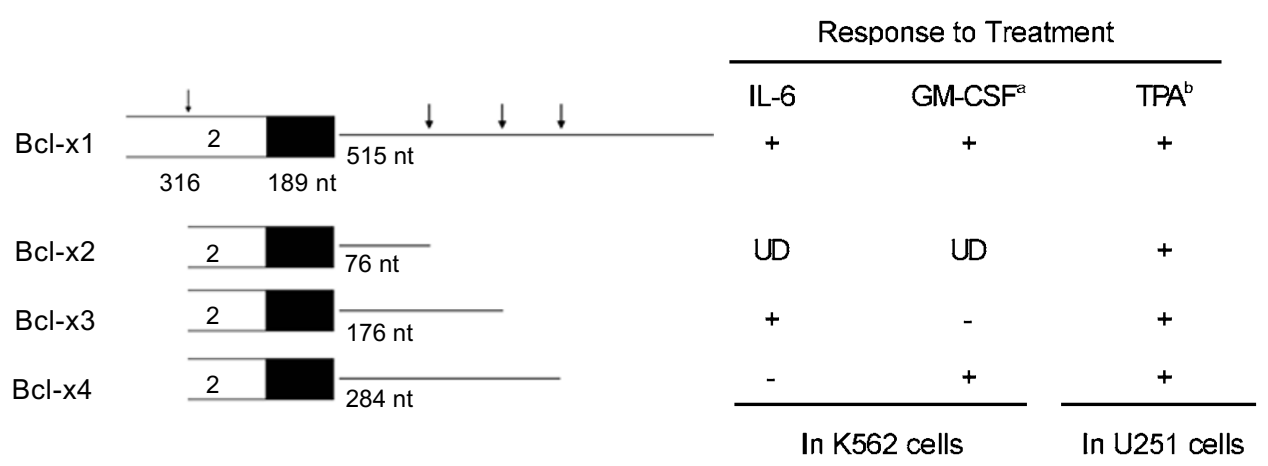

Fig. 4 Summary of the responses of the Bcl-x inserts ( 1 to 4 ) to the splicing regulations by IL-6, GM-CSF in K562 cells and by TPA in U251 cells. The nucleotides in the downstream introns are indicated. Arrows: cut-off sites of the mutants. Boxes: exons. Black box: $189 \mathrm{nt} \mathrm{Bcl-xL-specific} \mathrm{sequence.} \mathrm{UD:} \mathrm{unable} \mathrm{to} \mathrm{determine.} \mathrm{a:} \mathrm{repression} \mathrm{of} \mathrm{the} \mathrm{splicing} \mathrm{for} \mathrm{Bcl-xL.} \mathrm{b:} \mathrm{promotion} \mathrm{of} \mathrm{the}$ splicing for Bcl-xL.

regulation of Bcl-x splicing, including their known downstream targets involved in gene regulation $[28,29]$. For TPA, it activates the protein kinase $\mathrm{C}$ pathway to regulate alternative splicing of certain CD44 and CD45 exons [5, 6]. In our experiment, the TPA effect on Bcl-x splicing is completely blocked by erigeron breviscapus, a chemical reported to inhibit protein kinase $C[24,25]$. It is thus possible that the TPA effect on Bcl-x splicing is also through the PKC pathway.

The identification of minimal pre-mRNA segments for Bcl-x splicing regulations by different extracellular factors provides a starting point to further narrow down the precise RNA elements involved. The critical segments identified by deletions here are long enough to have multiple regulatory elements. Also the regions outside of the minimal inserts likely contain additional regulatory elements that are involved in the responses. For example, without additional regions from Bcl-x1, Bcl-x4 lost response to the regulations by IL-6 (Fig. 3). Therefore, further intensive mutagenesis analyses are necessary to identify the splicing enhancer or repressor elements involved.

The specific requirement of pre-mRNA segments for an extracellular factor to regulate Bcl-x splicing indicates that specific downstream components exist to mediate a particular regulation. For example, the intronic nucleotides 176-284 are specifically required for the GM-CSF effect. For the IL-6 effect, only the intronic 1-176 nts plus the upstream sequences in Bcl-x3 insert are sufficient. On the other hand, whether these three factors share elements in regulating Bcl-x splicing remains to be determined.

Promoter choice has been observed to affect the production of Bcl-x variant forms [30]. Whether the observed regulation of alternative splicing of Bcl-x is coupled with the transcriptional process needs to be examined. Since the plasmid constructs have the same stop codon when read from the transcripts, it is unlikely that the observed changes in Bcl-x variant mRNA forms are due to nonsense mediated decay [31].

In summary, with $\mathrm{Bcl}-\mathrm{xL} / \mathrm{Bcl}-\mathrm{xS}$ as targets, we found that splicing of the Bcl-xL variant mRNA was reduced by IL-6 and GM-CSF in K562 leukemia cells and increased by TPA in U251 glioma cells. The minimal pre-mRNA regions sufficient for the effects of these extracellular factors are different in mini-gene splicing reporter assays. It is likely that these factors have specific downstream targets in regulating Bcl-x splicing. Further investigations are required to identify the precise pre-mRNA elements and trans-factors involved, and to determine how the selection of the two alternative 5' splice sites in Bcl-x premRNA are regulated by these extracellular factors in generating the $\mathrm{Bcl}-\mathrm{xL}$ and $\mathrm{Bcl}-\mathrm{xS}$ splice variants.

\section{ACKNOWLEDGEMENTS}

This work was supported by the National Natural Science Foundation of China (No. 39993420) to Chu JY, and by the University of Manitoba to Xie JY.

Received, Feb 18, 2004

Revised, Sep 24, 2004

Accepted, Oct 5, 2004

\section{REFERENCES:}

1 Black DL. Mechanisms of Alternative Pre-Messenger RNA Splicing. Annu Rev Biochem 2003; 72:291-336.

2 Modrek B, Lee C. A genomic view of alternative splicing. Nat Genet 2002; 30:13-9. 
3 Black DL. Protein diversity from alternative splicing: a challenge for bioinformatics and post-genome biology. Cell 2000; 103:367-70.

4 Grabowski PJ, Black DL. Alternative RNA splicing in the nervous system. Prog Neurobiol 2001; 65:289-308.

5 Konig H, Ponta H, Herrlich P. Coupling of signal transduction to alternative pre-mRNA splicing by a composite splice regulator. EMBO J 1998; 17:2904-13.

6 Lynch KW, Weiss A. A model system for activation-induced alternative splicing of CD45 pre- mRNA in T cells implicates protein kinase C and Ras. Mol Cell Biol 2000; 20:70-80.

7 Weg-Remers S, Ponta H, Herrlich P, Konig H. Regulation of alternative pre-mRNA splicing by the ERK MAP-kinase pathway. EMBO J 2001; 20:4194-203.

8 Xie J, Black DL. A CaMK IV responsive RNA element mediates depolarization-induced alternative splicing of ion channels. Nature 2001; 410:936-9.

9 Rothrock C, Cannon B, Hahm B, Lynch KW. A conserved signalresponsive sequence mediates activation-induced alternative splicing of CD45. Mol Cell 2003; 12:1317-24.

10 Matter N, Herrlich P, Konig H. Signal-dependent regulation of splicing via phosphorylation of Sam68. Nature 2002; 420:691-5.

11 Jiang ZH, Wu JY. Alternative splicing and programmed cell death. Proc Soc Exp Biol Med 1999; 220:64-72.

12 Borner C. The Bcl-2 protein family: sensors and checkpoints for life-or-death decisions. Mol Immunol 2003; 39:615-47.

13 Boise LH, Gonzalez-Garcia M, Postema CE, et al. bcl-x, a bcl-2related gene that functions as a dominant regulator of apoptotic cell death. Cell 1993; 74:597-608.

14 Gonzalez-Garcia M, Garcia I, Ding L, et al. bcl-x is expressed in embryonic and postnatal neural tissues and functions to prevent neuronal cell death. Proc Natl Acad Sci U S A 1995; 92:4304-8.

15 Motoyama N, Wang F, Roth KA, et al. Massive cell death of immature hematopoietic cells and neurons in Bcl-x- deficient mice. Science 1995; 267:1506-10.

16 Reed JC. Splicing and dicing apoptosis genes. Nat Biotechnol 1999; 17:1064-5.

17 Mercatante DR, Bortner CD, Cidlowski JA, Kole R. Modification of alternative splicing of Bcl-x pre-mRNA in prostate and breast cancer cells. analysis of apoptosis and cell death. J Biol Chem 2001; 276:16411-7.

18 Taylor JK, Zhang QQ, Wyatt JR, Dean NM. Induction of endog- enous Bcl-xS through the control of Bcl-x pre-mRNA splicing by antisense oligonucleotides. Nat Biotechnol 1999; 17:1097100.

19 Gonzalez-Garcia M, Perez-Ballestero R, Ding L, et al. bcl-xL is the major bcl-x mRNA form expressed during murine development and its product localizes to mitochondria. Development 1994; 120:3033-42.

20 Xerri L, Parc P, Brousset P, et al. Predominant expression of the long isoform of Bcl-x (Bcl-xL) in human lymphomas. Br J Haematol 1996; 92:900-6.

21 Chalfant CE, Rathman K, Pinkerman RL, et al. De novo ceramide regulates the alternative splicing of caspase 9 and Bcl-x in A549 lung adenocarcinoma cells. Dependence on protein phosphatase1. J Biol Chem 2002; 277:12587-95.

22 Liu H, Ma Y, Li Z, et al. Cloning, expression and purification of human interleukin 6. J N Bethune Univ Med Sci 1999; 25:14-7 (In Chinese).

23 Li Z, Ji Q, Zhou L, et al. Purification of recombinant human granulocyte-macrophage colony stimulating factor expressed in Escherichia coli cells. Yunnan Med J 2001, 22:1-3 (In Chinese).

$24 \mathrm{Xu} \mathrm{G}$, Zhang L, Shen $\mathrm{H}, \mathrm{Hu}$ C. Inhibition of protein kinase $\mathrm{C}$ by scutellarein and its analogues. Acta Academiae Medicinae Shanghai 1993; 20:187-91 (In Chinese).

25 Zhu BH, Guan YY, He H, Lin MJ. Erigeron breviscapus prevents defective endothelium-dependent relaxation in diabetic rat aorta. Life Sci 1999; 65:1553-9.

26 Grillot DA, Gonzalez-Garcia M, Ekhterae D, et al. Genomic organization, promoter region analysis, and chromosome localization of the mouse bcl-x gene. J Immunol 1997; 158:4750-7.

27 Burge CB, Padgett RA, Sharp PA. Evolutionary fates and origins of U12-type introns. Mol Cell 1998; 2:773-85.

28 Geijsen N, Koenderman L, Coffer PJ. Specificity in cytokine signal transduction: lessons learned from the IL-3/IL-5/GMCSF receptor family. Cytokine Growth Factor Rev 2001; 12: 19-25.

29 Grad JM, Zeng XR, Boise LH. Regulation of Bcl-xL: a little bit of this and a little bit of STAT. Curr Opin Oncol 2000; 12:543-9.

30 Pecci A, Viegas LR, Baranao JL, Beato M. Promoter choice influences alternative splicing and determines the balance of isoforms expressed from the mouse $b c l-x$ gene. J Biol Chem 2001; 276:21062-9.

31 Maquat LE, Carmichael GG. Quality control of mRNA function. Cell 2001; 104:173-6. 